the consultants and staff of the drug dependence clinics, who have been generous in their help over the years.
${ }^{4}$ Chapple, P A L, Somekh, D E, and Taylor, M E, British fournal of Addiction, 1972, 67, 33.

5 Waldorf, D, Social Problems, 1970, 18, 228.

${ }^{6}$ Vaillant, G E, Archives of General Psychiatry, 1973, 20, 237.

7 Stimson, G V, and Ogborne, A C, Lancet, 1970, 1, 1163.

Ogborne, A C, and Stimson, G V, International fournal of Addiction, 1975 10,1061

9 Thorley, A, Oppenheimer, E, and Stimson, G V, British fournal of Psychiatry, 1977, 130, 565.

(Accepted 26 fuly 1979)

\title{
New mechanical aid to physiotherapy in cystic fibrosis
}

\author{
K A FLOWER, R I EDEN, L LOMAX, N M MANN, JEAN BURGESS
}

British Medical fournal, 1979, 2, 630-631

\section{Summary and conclusions}

The force of impact and frequency of percussion by physiotherapists and parents of children with cystic fibrosis were analysed on a special test rig and incorporated in a prototype percussor. In adult volunteers and cadavers a maximum intrathoracic pressure could be achieved by a critical frequency of mechanical percussion which was higher than that reached by physiotherapists and parents. Consequently the percussor was redesigned to operate at this optimum frequency. It was then discovered that if the percussor was pressed firmly enough against the chest, this maximum intrathoracic pressure could be indicated by quivering of the voice. In a continuing study of intrathoracic pressures obtained mechanically and manually the Salford percussor produced higher pressures than the physiotherapists' and maintained them constantly, while the physiotherapists' efforts and results varied from one to another. Hospital and domiciliary use of the percussor have shown it to help in the first stage of the physiotherapy routine for patients with cystic fibrosis.

The percussor should enable adolescents and adults to treat themselves and encourage twice-daily and more effective chest treatment. It is easy to apply and its speed and efficiency should enable parents to improve the quality of their chest therapy for younger children at home. Its long-term benefits are difficult to assess because of the nature of the disease.

\section{Introduction}

Physiotherapy is a vital part of the management which has extended the life expectancy of patients with cystic fibrosis. ${ }^{1-3}$

\footnotetext{
Department of Aeronautical and Mechanical Engineering, University of Salford, Salford M5 4WT

K A FLOWER, MSC, PHD, lecturer

R I EDEN, $M B$, CHB, research student

L LOMAX, BSC, research studen

Royal Manchester Children's Hospital, Pendlebury M27 1HA

N M MANN, MD, FRCPED, consultant paediatrician

JEAN BURGESS, MCSP, SRP, senior physiotherapist
}

The main components of physiotherapy to segments of the lung during postural drainage are percussion, assisted panting, squeezing, and shaking of the chest. The secretions loosened in this way are removed by spontaneous or controlled coughing. The best chest treatment is given by physiotherapists in hospitals and their outpatient departments but most chest therapy is given at home. Capable and conscientious parents, however, may be handicapped if they have more than one child with cystic fibrosis or are themselves unwell. Less co-operative parents cannot be relied on to apply twice-daily and efficient chest treatment. When children reach adolescence they may resent their dependence on their family and other people for treatment, which can then become haphazard. Mechanical aids to chest treatment should meet some of these needs to allow a more independent life.

\section{Patients and methods}

Experimental apparatus was built to measure the speed and the force of impact of percussion of physiotherapists and parents of children with cystic fibrosis. The test rig consisted of a mild steel beam supported by adjustable end-mounts. A curved block representing the chest was fixed on to the centre of the beam. A transducer was mounted under the curved block and its output fed to a recorder. The compliance of the steel bar was adjusted so that it was judged by the physiotherapists to resemble the compliance of a chest. The "chest" was then percussed by physiotherapists and parents with their usual technique. The trace from the recorder was analysed for speed and force of percussion. The results enabled a first generation of prototype percussors to be developed which were driven by air to reproduce the speed and force of percussion. These failed, however, because the air compressors proved ineffective.

At this time, the relation of the frequency of percussion to the intrathoracic pressure produced by it was investigated. The tracheas of 22 adult cadavers (aged 44 to 68 years) were intubated with Foley catheters. A low-pressure transducer was connected to the catheter and to a recorder. Nine volunteers (aged 18 to 38 years) swallowed oesophageal balloons and by similar transducer techniques the intrathoracic pressures created by percussion were recorded. We discovered that the curves obtained were identical and a maximum intrathoracic pressure could be achieved by a critical frequency of percussion signified by vibration of the voice (fig 1). Therefore, a second generation of prototype percussors was designed but based on a reciprocating movement found in a portable but modified jig saw. This enabled the speed of percussion to be increased to the optimum value discovered in the intrathoracic pressure experiments. A $68-\mathrm{mm}$ diameter rubber cup with a depression of $6 \mathrm{~mm}$ fitted to the percussor shaft delivered the percussion.

In a second and continuing study of intrathoracic pressures during physiotherapy on an examination couch the percussor was compared with three physiotherapists and the pressures recorded in the Wilhel- 
mina Children's Hospital, Utrecht, in association with Drs J Van der Laag and J D Van Gool and Mr P J M Helders, superintendent physiotherapist (fig 2).

\section{Results}

The frequency of percussion attained by physiotherapists depended on their special skills. They could be divided into two groups. A physiotherapist whose chief duty was the daily treatment of chests percussed at the rate of $450-480$ beats per minute. The physiotherapist with duties other than chest percussion produced a frequency of 250-360 beats per minute. The trained parents of children with cystic fibrosis reached the higher percussion rate. The force of percussion was constant and ranged from 58 to 65 Newtons. The force of the percussor was equivalent to the force of impact of the hands of the physiotherapist but did not exceed it. The maximum intrathoracic pressure was achieved when the percussor was pressed firmly and at right angles to the chest wall to make the voice quiver. The percussor was shown to maintain a higher and more constant intra-

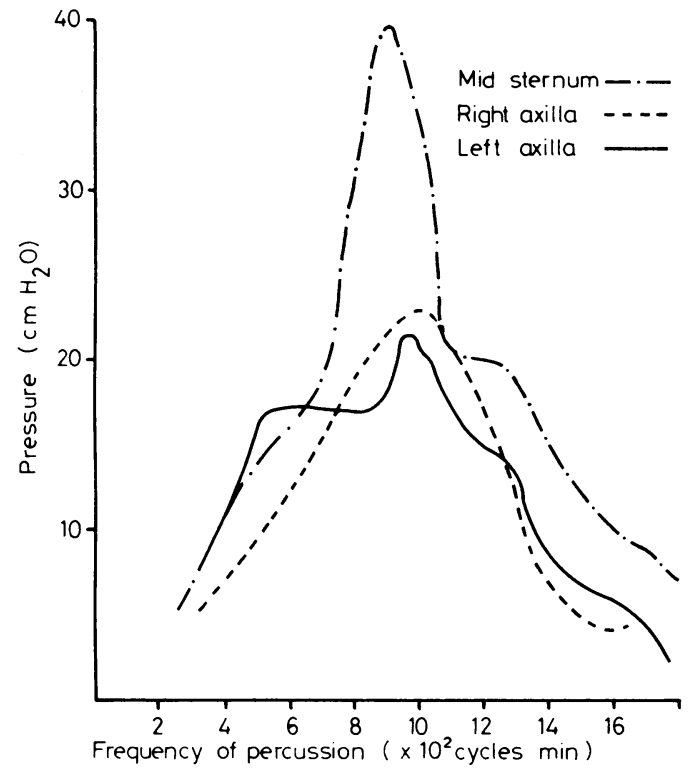

FIG 1 -Relation between intrathoracic pressure and frequency of percussion.

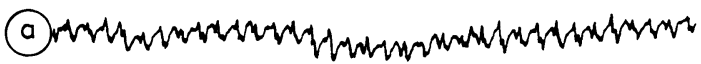

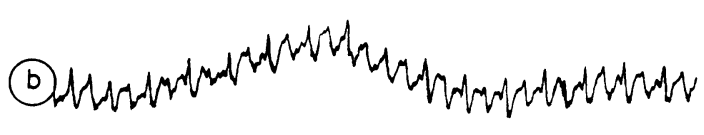
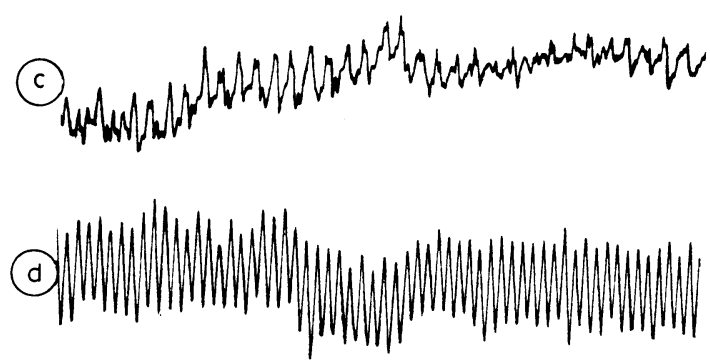

FIG 2-Traces of intrathoracic pressures. Tracings $a, b$, and $c$, showing differences in pressures of $11.5 \mathrm{~cm} \mathrm{H} \mathrm{H}_{2} \mathrm{O}, 13.5 \mathrm{~cm}$ $\mathrm{H}_{2} \mathrm{O}$, and $15.4 \mathrm{~cm} \mathrm{H}_{2} \mathrm{O}$ respectively, were produced manually by physiotherapists (tracings $a$ and $b$ were produced by Dutch female and male physiotherapists respectively, and tracing $c$ by a British female physiotherapist). Tracing $d$, showing a difference in pressure of $36.5 \mathrm{~cm} \mathrm{H}_{2} \mathrm{O}$, was produced by the Salford percussor. thoracic pressure of 25 to $30 \mathrm{~cm} \mathrm{H}_{2} \mathrm{O}$. In comparing the performance of three physiotherapists, two women and one man, with that of the Salford percussor, the women generated pressures of about $5 \mathrm{~cm}$ and $15 \mathrm{~cm} \mathrm{H}_{2} \mathrm{O}$ and the man about $12 \mathrm{~cm} \mathrm{H}_{2} \mathrm{O}$. None of these pressures were as constant as those of the percussor. In hospital the percussor was found to be acceptable to both the patients and the physiotherapists and increased the removal of mucopus. No adverse effects on the heart were noticed and the electrocardiograms remained unchanged.

\section{Discussion}

Some parents of mildly affected children cannot be convinced of the need for chest treatment, while others with more than one affected child are sometimes not far from despair. The adolescent and adult come to resent dependence on others for their treatment; similar distress has been noticed in patients with bronchiectasis from other causes. ${ }^{4}$ Inevitably mechanical aids have been developed and reported to be especially useful for older patients, but their specifications are not mentioned. ${ }^{5}$

This would appear to be the first time that the chest percussion treatment given by physiotherapists has been analysed. The results have been reproduced in the Salford Percussor, which is small, portable, and lightweight $(1.6 \mathrm{~kg})$. The simple test of obtaining voice quiver (or the Dalek effect) ensures that the percussor has been applied with sufficient firmness to obtain the maximum intrathoracic pressure for effective percussion of the chest. Intrathoracic pressures in children have not been measured. At home all the parents found the percussor easy to use. In a disease so variable in its effects and so inexorably progressive in severe cases it may be difficult to find ways of measuring the effectiveness of mechanical percussion even over a long period of time. Nevertheless, clinical trials are being planned.

The details of the equipment used for investigation, the design drawing, and the calculation of the force of percussion will be sent on request.

We thank Miss Ann Grimley, superintendent physiotherapist, for her constant support and Mrs Leslie Willescroft for her contribution to the preliminary studies.

We are grateful for the generous financial support given over the last three years by the Cystic Fibrosis Research Trust. Part of this paper was read at the Eighth European Working Group Cystic Fibrosis Meeting at Bad Gastein, Austria, in June 1978.

\section{References}

${ }_{1}$ Schwachman, H, Kowalski, L L, and Khaw, K T, Cystic Fibrosis Club Abstracts 13. Atlanta, Georgia, National Cystic Fibrosis Research Foundation, 1974.

2 Norman, A P, and Robinson, M J, Archives of Disease in Childhood, 1975, 50, 962.

${ }^{3}$ Crozier, D N, Pediatric Clinics of North America, 1974, 21, 935.

${ }^{4}$ Hodson, M E, British Medical fournal, 1978, 1, 971.

5 I ough, M D, Doershuk, C F, and Stern, R C, editors, Pediatric Respiratory Therapy, p 148. Chicago. Year Book Medical Publishers, 1974.

(Accepted 26 fuly 1979)

ONE HUNDRED YEARS AGO At the farm of Cairnbrogil, Tarves, Aberdeenshire, Mr Man (the tenant), Mrs Man, Miss Eliza Man, and two domestic servants, were seized with sickness and violent vomiting shortly after dinner. A medical man was called in, and came to the conclusion that the illness was due to poisoning. They ultimately recovered, although Mrs Man and one of the servants continued sick till next day. The only explanation that can be given of the case is that, on the previous night, Mrs Man had mixed some vermin-poison with suet and oatmeal, and that some of this had been carried by the rats and mixed with the potatoes (in this same pantry) which were used for dinner by those next day who became affected. (British Medical fournal, 1879.) 